\title{
PENGARUH PENERAPAN METODE PEER TUTORING TERHADAP PEMAHAMAN MATEMATIS SISWA MTS
}

\author{
Yuni Mahmudah ${ }^{1}$, Lia Saniah ${ }^{2}$ \\ ${ }^{1}$ MTsN 2 Bandung Barat ${ }^{2}$ Universitas Putra Indonesia (UNPI) Cianjur \\ yunimahmudah25@gmail.com, liasaniah@unpi-cianjur.ac.id
}

\begin{abstract}
ABSTRAK
Penelitian ini dilakukan mengingat pentingya kemampuan pemahaman matematika dalam pembelajaran matematika. Dalam mempelajari matematika tidak cukup hanya dengan menghafal rumus-rumus saja, tetapi membutuhkan pengertian, pemhaman dan keterampilan secara mendalam. Untuk memahami konsep matematka yang bersifat abstrak dibutuhkan aktifitas dan kreatifitas yang tinggi dari siswa. Oleh sebab itu pembelajaran harus diarahkan agar dapat membangkitan kreatifitas siswa tersebut. Salah satu metode pembelajaran yang dapat dilakukan untuk mengatasi kendala-kendala di atas adalah metode pembelajaran peer tutoring (metode tutor sebaya). Metode peer tutoring ini yaitu pembelajaran yang dilakukan dengan cara memberdayakan kemampuan siswa yang memiliki daya serap yang tinggi, siswa tersebut mengajarkan materi/latihan kepada teman-temanya yang belum paham. Berdasarkan hal tersebut penelitian ini bertujuan untuk mengetahui pengaruh metode peer tutoring terhadap pemahaman matematis siswa MTs. Adapun metode penelitian yang digunakan yaitu metode eksperimen. Teknik pengumpulan data pada penelitian ini dengan menggunakan tes awal dan tes akhir. Penelitian dilakukan terhadap 64 siswa MTs kelas VIII yang dibagi kedalam dua rombongan belajar. Berdasarkan penelitian, dapat disimpulkan bahwa, antara kelompok eksperimen dan kelompok kontrol terdapat perbedaan kemampuan pemahaman matematis antara siswa yang belajar matematika menggunakan metode peer tutoring dengan siswa yang belajar dengan menggunakan metode konvensional.
\end{abstract}

Kata Kunci: Peer Tutoring, Pemahaman Matematis, Madrasah Tsanawiyah

\section{PENDAHULUAN}

Pendidikan memiliki peranan yang sangat penting dalam menghadapi kehidupan yang terus berkembang. Sejalan dengan perkembangan masyarakat dewasa ini, sangat dibutuhkan sumber daya manusia yang handal dan mampu berkompetensi untuk memenuhi tuntunan akan perkembangan ilmu pengetahuan dan teknologi yang diakui sangat pesat. Tentunya peningkatan mutu pendidikan harus terus selalu diupayakan guna menjadikan sumber daya manusia yang berkualitas. Seharusnya, ini menjadi sebuah perhatian para pelaku pendidikan yang terkait untuk memperbaiki kualitas pendidikan sehingga tujuan pendidikan dapat tercapai. Hal demikian seperti tercantum dalam undang-undang No. 20 Tahun 2003 tentang sistem pendidikan nasional.

"Pendidikan adalah usaha sadar dan tercantum untuk mewujudkan suasana belajar dan proses pembelajaran agar pseserta didik secara aktif mengembangkan potensi 
dirinya untuk memiliki kekuatan spiritual keagamaan, pengendalian diri, kepribadian, kecerdasan, akhlak mulia, serta keterampilan yang diperlukan dirinya, masyarakat, bangsa dan negara."

Pada dasarnya pendidikan marupakan suatu proses untuk membantu manusia mengembangkan diirinya sehingga mampu menghadapi segala perubahan yang terjadi. Pendidikan diartikan sebagai interaksi antara faktor-faktor yang terlibat didalamnya untuk mencapai tujuan pendidikan (Surya, 2004: 4). proses sederhana yang menggambarkan interaksi unsur pendidikan secara jelas dilihat dalam proses belajar yang terjadi di lembaga pendidikan formal, yaitu sekolah. Dalam proses pembelajaran siswa didik untuk menjadi manusia yang cerdas dan terampil serta merupakan suatu tumpuan yang mampu menghantarkan kepada keberhasilnya hidupnya, dalam rangka meningkatkan sumber daya manusia. Salah satu mata pelajaran yang memiliki peranan penting dalam pendidikan masyarakat adalah pembelajaran matematika.

Matematika didefinisikan sebagai ilmu yang universal karena keberadaanya mendasari perkembangan teknologi moderen serta mempunyai peranan yang sangat penting dalam berbagai disiplin ilmu dan memajukan daya pikir manusia. Matematika merupakan suatu cara yang digunakan untuk pemecahan masalah dalam kehidupan sharihari, memulai bahasa simbiosi yang universal, dan mencakup lambang, bilangan, bentuk, ukuran. Setiap orang akan memaknai setiap lambang dan angka dengan paham yang berbeda karena lambang dan angka pada matematika kaya akan makna.

Matemik merupakan salah satu bidang studi yang menduduki pernan penting dalam pendidikan. Hal ini dapat dilihat dari waktu jam pelajaran sekolah lebih banyak dibanding pelajaran lain. Pelajaran matematika dalam pelaksanaan pendidikan diberikan kepada semua jenjang pendidikan mulai dari taman kanak-kanak sampai sekolah menengah atas,bebagai alasanya perlunya sekolah mengajarkan matematika kepada siswa. Pada dasarnya dapat diringkaskan bahwa hal ni dikarenakan oleh masalah kehidupan sehari-hari.

Salah satu hambatan dalam pelajaran matemika adalah bahwa siswa kurang tertarik pada matematika. Banyak siswa yang mengalami kesulitan bila mengahadpi soal-soal matematika. Matematika sering dimaknai sebagai sesuatu yang mutlak, seolah-olah tidak ada kemungkinan cara dan jawaban lain yang berbeda-beda. Siswa yang mempelajari matematika di sekolahpun menerima pelajaran ini sebagai sesuatu yang mesti tepat dan tidak sedikitpun boleh salah. Sehingga matematika diangap sebagai beban bahkan menjadi sesuatu hal yang menakutkan bagi siswa. Hal ini dapat mengakibatkan prestasi belajar matematika sangat rendah bila dibandingkan dengan mata pelajaran lain. 
Salah satu metode pembelajaran yang dapat dilakukan untuk mengatasi kedalankendala diatas adalah metode pembelajaran peer tutoring (metode tutor sebaya). Metode peer tutoring ini yaitu pembelajaran yang dilakukan dengan cara memberdayakan kemampuan siswa yang memiliki daya serap yang tinggi, siswa tersebut mengajarkan materi/latihan kepada teman-temanya yang belum paham. Pada metode peer tutoring ini siswa akan belajar kepada sesama temanya, sejalan dengan yang diungkapkan oleh Djamarah dan Zain (2006:25) bahwa "adakalanya seorang siswa lebih mudah menerima keterangan yang diberikan oleh temanya"

Dengan demikian penggunan metode pembelajaran tutor sebaya ini diupayakan tepat dapat meningkatkan kecapakan siswa dalam berkomunikasi dan juga dapat memberi solusi kepada siswa dalam memahami suatu konsep mata pelajaran sehingga dapat meningkatkan pemahaman matematika mereka. Meier (2005:62) mengemukakan bahwa pada suatu telaah di Stanford University ditemukan bahwa bimbingan belajar oleh kawan itu empat kali lebih efektif untuk meningkatkan prestasi belajar di bidang mateamtika dan membaca dibandingkan jika jumlah kelas dikurangi atau waktu pengajaran diperpanjang, dan jauh lebih efektif dibandingkan dengan intruksi individual dengan komputer.

Hal ini menunjukan bahwa tutor sebaya memiliki peranan yang penting karena memiliki pengaruh yang sangat berarti terhadap proses pembelajaran. Pembalajaran tutor sebaya dapat dilakukan di berbagai tingkatan pendidikan. Selain itu, penerapan metode ini juga tidak terbatas pada pokok bahan tertentu. Sehingga dalam setiap jenjang pendidikan dapat diterapkan model pembelajaran tutor sebaya tanpa harus terancang pada suatu pokok bahasan tertentu.

\section{METODE PENELITIAN}

Metode yang digunakan dalam penelitian ini adalah metode eksperimen. Furchan (2007:337) menyatakan bahwa "eksperimen adalah kegiatan yang direncanakan dan di laksanakan oleh penelitian untuk mengumpulkan bukti-bukti yang ada hubunganya dengan hipotesis". dalam penelitian eksperimen, peneliti mencurahkan segala perhatianya pada manipulasi variabel dan kontrol terhadap varibel-variabel lainya serta mengukur hasilhasilnya (Sujdana dan Ibrahim, 2004:19)

Dalam penelitian ini, peneliti akan membandingkan kemampuan pemahaman matematis melalui pembelajaran dengan menerapkan metode peer tutoring dan pembelajaran konvensional. Perbandingan ini dilihat dari perbedaan rata-rata hasil belajar siswa pada kedua kelompok tersebut. Maka yang menjadi variabel bebasnya adalah metode 
peer tutoring sedangkan yang menjadi varibel terikatnya adalah kemampuan pemahaman matematika siswa.

Desain yang digunakan oleh penelitian adalah desain eksperimen semu (Quasi Eksperiental Designs) yaitu desain yang menggunakan pretes (tes awal) dan postes (tes akhir) dengan kelompok pengendali tidak diacak. Peneliti menggunakan kelompok subjek seperti apa adanya. Sesuai yang diungkapkan oleh Ruseffendi (2006:52) bahwa "pada kuasi eksperimen subjek tidak dikelompok secara acak, tetapi peneliti menerima keadaan subjek seadanya".

Pada desain eksperimen ini terapat pretes, pelakuan yang berbeda dan juga postes, seperti yang ditunjukan pada Tabel 1.

Tabel 1. Desain Eksperimental Semu

\begin{tabular}{cccc}
\hline Kelompok & Pretes & Varibel Bebas & Postes \\
\hline Eksperimen & Y1 & $\mathrm{X}$ & Y2 \\
Kontrol & Y1 & - & Y2 \\
\hline
\end{tabular}

Sumber: Furchan, $2007: 395$

Adapun yang menjadi populasi dalam penelitian ini adalah seluruh siswa kelas VIII MTs Negeri 2 Bandung Barat Tahun Ajaran 2019-2020. peneliti memilih populasi siswa kelas VIII merupakan kelas yang berada di tingkat pertengahan antara kelas VII dan IX. Selain itu siswa kelas VIII juga belum disibukan dengan kegiatan mempersiapkan diri untuk mengikuti Ujian Nasional.

Peneliti ini menggunakan desain eksperimen semu yang pada pemilihan sampel tidak melakukan teknik pengacakan, maka peneliti mengguanakan kelas yang telah ada. Diantara beberapa kelas VIII yang ada, peneliti mengambil dua kelas. Menurut guru pamong, kedua kelas ini memiliki tingkat kemampuan yang hampir sama dan begitu pula jumlah siswa kedua kelas pun sama.

Tabel 2. Jumlah Siswa Yang Dijadikan Sampel

\begin{tabular}{cccc}
\hline Kelas & Siswa Laki-laki & Siswa Perempuan & Jumlah \\
\hline Eksperimen & 15 & 17 & 32 \\
Kontrol & 16 & 16 & 32 \\
Jumlah & 31 & 37 & 64 \\
\hline
\end{tabular}

\section{HASIL DAN PEMBAHASAN}

\section{Data Pretes Pemahaman Matematis Siswa}

Sebelum pelasankanaan pembelajaran, peneliti melakukan pretes kepada kelompok eksperimen dan kelompok kontrol. Hal ini dilakukan untuk melihat kemampuan awal siswa dari kedua kelompok tersebut. Statistik deskriptif hasil pretes yang telah dilakukan disajikan pada Tabel 3. 
Tabel 3. Statistik Deskriptif Nilai Pretest Kelompok Ekspermien dan Kelompok Kontrol

\begin{tabular}{lllllll}
\hline & N & Min & Max & Mean & Std. Dev. & Variance \\
\hline Pretest Eksperimen & 34 & 2.00 & 55.00 & 20.7353 & 11.87896 & 141.110 \\
Pretsest Kontrol & 34 & .000 & 64.00 & 17.0294 & 13.10213 & 171.666 \\
\hline
\end{tabular}

Sumber : Olah data SPSS17.0,2010

Dari hasil pretes yang diberikan didapat rata-rata untuk kelompok eksperimen adalah 20,73 dengan simpangan bakunya 11,87 sedangkan kelompok kontrol rata-rata nilai yang diperoleh adalah 17,02 dan simpangan bakunya adalah 13,10. dilihat dari sebaran data kelasnya

Untuk penguji normalitas, peneliti menggunakan program SPSS 17 for windows dengan teknik Kolmogorov-Smirnov test (Agung, 2010:141). Uji Normalitas dilakukan untuk mengetahui apakah data terdistribusi secara normal atau tidak. Data dikatakan berdistribusi normal jika memiliki nilai sig. > 0,05. Hasil output SPSS mengenai uji normalitas data hasil pretes disajikan pada Tabel 4.

Tabel 4. Uji normalitas Data Pretes dengan Teknik Kolmogorov-Smirnov

\begin{tabular}{llrr}
\hline & & $\begin{array}{c}\text { Pretes } \\
\text { eksperimen }\end{array}$ & Pretes Kontrol \\
\hline $\mathrm{N}$ & Mean & 32 & 32 \\
Normal Parameters ${ }^{a, b}$ & Std. Deviation & 20.7353 & 17.0294 \\
& Absoult & 11.87896 & 13.10213 \\
Most Extreme Differences & Positive & .181 & .209 \\
& Negative & .181 & .209 \\
& Kolmogorov-Smirnov Z & -.095 & -.119 \\
& Asymp. Sig.(2-tailed) & 1.057 & 1.216 \\
& & .214 & .104 \\
\hline
\end{tabular}

a. Test distribution is Normal

b. Calculated from data

Berdasarkan hasil analisis yang diajukan pada Tabel 4 diperoleh nilai sig. Pretes kelompok eksperimen adalah 0,214. dan nilai sig pretes kelompok kontrol adalah 0,104. kedua nilai sig tersebut menyatakan lebih besar dari $\alpha=0,05$. maka dapat disimpulkan bahwa $H_{0}$ diterima, artinya data berasal dari populasi yang berdistribusi normal.

Dari deskripsi tabel uji normalitas nilai pretes kelompok eksperimen dan kelompok kontrol yang telah disajikan pada Tabel 4, dapat juga dikonversikan dalam bentuk diagram batang. Untuk lebih jelasnya dapat dilihat pada Gambar 1 dan Gambar 2. 


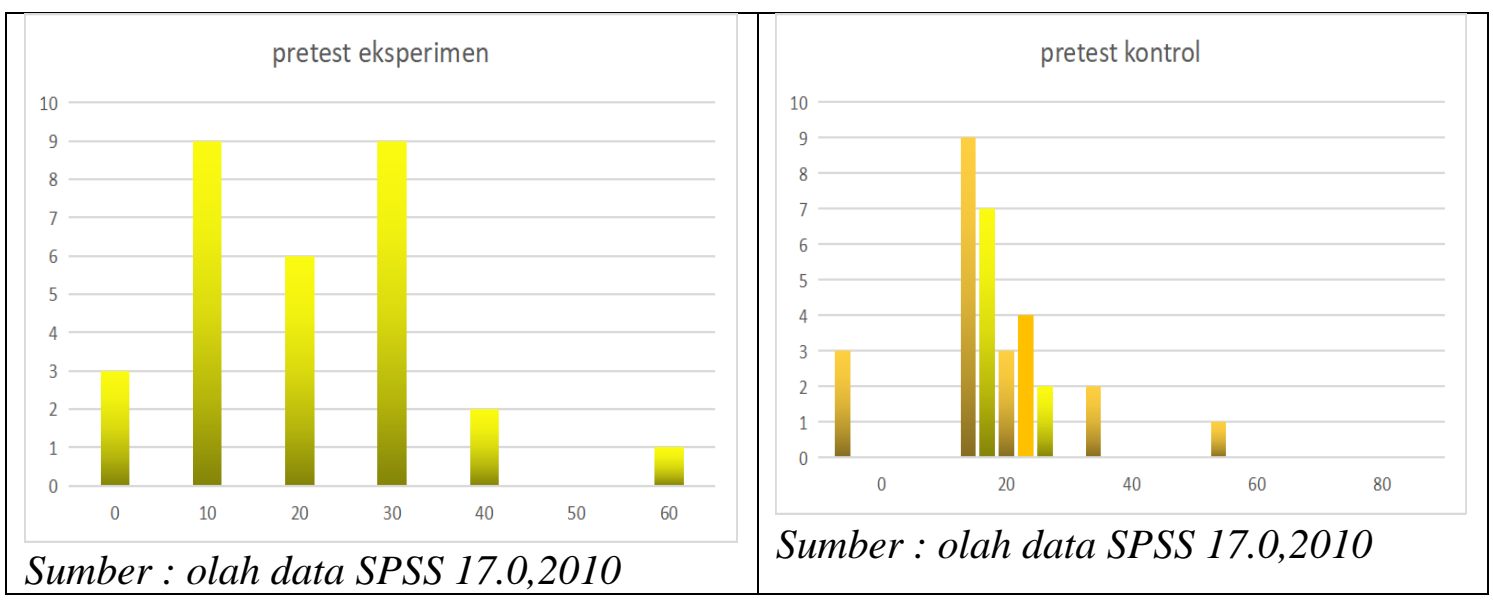

Gambar 1

Diagram Data Hasil Pretes

Kelompok Eksperimen
Gambar 2

Diagram Data Hasil Pretes

Kelompok Kontrol

Dari hasil konversi data ke dalam bentuk diagram batang dapat dilihat bahwa data pretes pada kelompok eksperimen mengikuti alur garis normal (Gambar 1). begitu pula dengan data pretes kelompok kontrol (Gambar 2). juga menunjukkan bahwa data mengikuti alur garis normal.

Tabel 5. Uji t Nilai Pretes Kedua Kelas

\begin{tabular}{lcccc}
\hline Equal Variances & $\mathrm{T}$ & $\mathrm{df}$ & Sig.(2-tailed) & Keterangan \\
\cline { 2 - 5 } Assumed & 2.519 & 62 & 0.363 & $\mathrm{H}_{0}$ diterima \\
\hline
\end{tabular}

Berdasarkan Tabel 5 hasil uji perbedaan dua rata-rata menunjukan nilai sig. $0.363>$ 0.05 dengan demikian $\mathrm{H}_{0}$ diterima. Artinya, tidak terdapat perbedaan kemampuan awal pemahaman matematis antara siswa kelas eksperimen dan siswa kelas kontrol.

\section{Data Postes Pemahaman Matematis Siswa}

Setelah proses pembelajaran selesai, maka langkah selanjutnya adalah pemberiaan postes kepada kelompok eksperimen dan kelompok kontrol. Dari hasil postes didapat ratarata dan simpangan baku yang telah disajikan pada Tabel 6.

Tabel 6.

Statistika Deskriptif Data Nilai Postes Kelompok Eksperimen Dan Kelompok Kontrol

\begin{tabular}{lcccccc}
\hline & N & Min & Max & Mean & Std. Dev & Variance \\
\hline Pretest Eksperimen & 32 & 13.00 & 100.00 & 58.0588 & 23.49331 & 141.110 \\
Pretsest Kontrol & 32 & 10.00 & 96.00 & 35.6471 & 19.48408 & 171.666 \\
\hline
\end{tabular}

Pada Tabel 6 dapat dilihat bahwa rata-rata pada kelompok eksperimen 58,0588 dengan simpangan baku 23,49331. Hal ini berarti penyeberan data kurang homogen dibandingkan dengan kelas kontrol yang mempunyai rata-rata 35,6471 dan simpangan baku 19,484808 . 
Untuk pengujian normalitas, peneliti menggunkan program SPSS 17.0 for Windows dengan teknik Kolmogorov-Smirnov Test (Agung, 2010:141). Data dikatakan berdistribusi normal jika memiliki nilai sig. > 0,05 (Uyanto, 2009:40). hasil output SPSS mengenai uji normalitas data postes disajikan pada Tabel 7.

Tabel 7.

Uji Normalitas Data Postes Dengan teknik Kolmogorov-smirnov

\begin{tabular}{|c|c|c|c|}
\hline & & $\begin{array}{l}\text { Postes } \\
\text { eksperimen }\end{array}$ & Postes Kontrol \\
\hline $\mathrm{N}$ & & 32 & 32 \\
\hline \multirow{2}{*}{ Normal Parameters ${ }^{a, b}$} & Mean & 58.0588 & 356471 \\
\hline & Std. Deviation & 23.49331 & 19.48408 \\
\hline \multirow{3}{*}{ Most Extreme Differences } & Absoult & .092 & .158 \\
\hline & Positive & .092 & .158 \\
\hline & Negative & -.083 & -.094 \\
\hline \multicolumn{2}{|c|}{ Kolmogorov-Smirnov Z } & .537 & .920 \\
\hline \multicolumn{2}{|c|}{ Asymp. Sig.(2-tailed) } & .935 & .365 \\
\hline
\end{tabular}

a. Test distribution is Normal

b. Calculated from data

Sumber : Olah data SPSS 17.0, 2010

Berdasarkan hasil analisis yang telah disajikan pada Tabel 7 diperoleh kelompok eksperimen adalah 0,935 dan nilai sig postes kelompok kontrol 0,365. Nilai sig kelompok eksperimen lebih besar dari $\alpha=0,05$ begitupun dengan nilai sig pada kelompok kontrol. Maka dapat disimpulkan bahwa $H_{0}$ diterima, artinya data berasal dari populasi yang berdistribusi normal.

Dari deskripsi tabel uji normalitas nilai postes kelompok eksperimen dan kelompok kontrol yang telah disajikan pada Tabel 7, dapat pula dikonversikan dalam bentuk diagram batang. Untuk lebih jelasnya dapat dilihat pada Gambar 3 dan Gambar 4.

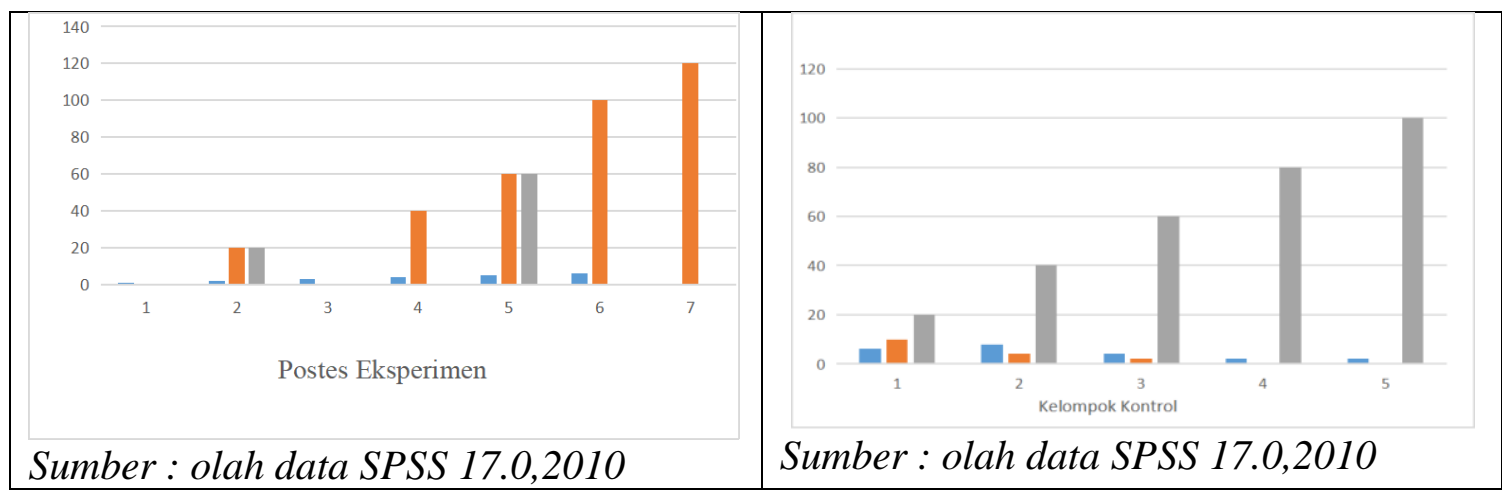

Gambar 3

Diagram data hasil postes

Kelompok eksperimen
Gambar 4

Diagram data hasil postes

Kelompok Kontrol

Dari hasil konversi data ke dalam bentuk diagram batang dapat dilihat bahwa data postes pada kelompok eksperimen mengikuti alur garis normal (Gambar 3). begitu pula dengan data postes kelompok kontrol (Gambar 4) juga menunjukan bahwa data mengikuti alur garis normal. 
Tabel 8. Uji t Nilai Postes Kedua Kelas

\begin{tabular}{lcccc}
\hline Equal Variances & $\mathrm{T}$ & $\mathrm{df}$ & Sig.(2-tailed) & Keterangan \\
\cline { 2 - 5 } Assumed & 2.519 & 62 & 0.014 & $\mathrm{H}_{0}$ ditolak \\
\hline
\end{tabular}

Berdasarkan Tabel 8 hasil uji perbedaan dua rata-rata menunjukan nilai sig. $0.014<$ 0.05 dengan demikian $\mathrm{H}_{0}$ ditolak. Artinya, terdapat perbedaan kemampuan pemahaman matematis siswa yang belajar menggunakan Model Pembelajaran Peer Tutoring dengan kemampuan pemahaman matematis siswa yang belajar menggunakan model pembelajaran konvensional.

\section{KESIMPULAN}

Berdasarkan hasil peneltian melalui analisis data pengujian hipotesis maka dapat di tarik kesimpulan bahwa pembelajaran matematika dengan menggunakan metode peer tutoring ternyata mampu meningkatkan kemampuan pemahaman matematis siswa MTs. Hal ini dapat dilihat dari hasil tes siswa setelah diberikan perlakuan. Dari data nilai hasil tes setelah diberikan perlakuan yang berbeda kepada kelompok eksperimen dan kelompok kontrol, terlihat jelas bahwa kedua kelompok tersebut memiliki nilai rata-rata yang cukup signifikan. Kelompok eksperimen yang diberikan perlakuan dengan menggunakan metode peer tutoring ternyata memiliki nilai rata-rata yang lebih tinggi dibandingkan dengan kelompok kontrol yang pembelajrannya menggunakan metode konvensonal. Padahal sebelum keduanya diberikan perlakuan yang berbeda, nilai rata-rata hasil tes antara kedua kelompok tersebut relatif sama. Maka dapat disimpulkan bahwa penerapan metode peer tutoring dapat meningkatkan kemampuan pemahaman matematik siswa Mts.

\section{REFERENSI}

Agung, W, (2010). Panduan SPSS Untuk Mengolah Penelitian Kuantitatif. Yogyakarta : Gerai ilmu

Depdiknas (2006). Standar Kompentensi dan Kompentensi Dasar Mata Pelajaran Matematika Sekolah Menengah Pertama dan Madrosah Tsanawiah. Jakarta: Badan Standar Nasional Pendidikan (BSNP) dan Direktorat Pembinaan MTS Ditjen Mendikdasmen Depdiknas.

Djamarah \& Zain. (2006). Strategi belajar mengajar. Jakarta: Rineka Cipta.

Furchan, (2007). Pengantar Penelitian dalam Pendidikan. Malang : Pustaka Pelajar. Meier, D. (2005). The Accelerated Learning Handbook. Bandung : Kaifa.

Nustika, S. (2006). Pengaruh Pembelajaran Matematika Melalui Model Siklus Belajar Dengan Bantuan Tutor Sebaya dan Tanpa Bantuan Tutot Sebaya Terhadap Hasil Belajar Siswa di SMK. Skripsi FPMIPA UPI. Tidak diterbitkan

Sudjana \& Ibrahim.2004. Penelitian dan Penilaian Pendidikan. Bandung: Sinar Baru Algesindo.

Sudjana, N. dan Ibrahim. (2004). Penelitian dan Penilaian Pendidikan. Cetakan. Ketiga. Bandung : Sinar Baru Algesindo. 
Sukardi. 2007. Metodologi Penelitian Pendidikan. Jakarta : Bumi Aksara.

Sugiyono. 2009. Statistika Untuk Penelitian, Bandung:Alfabeta.

Surya, M. (2004). Psikologi Pembelajaran dan Pengajaran. Bandung: Pustaka Bani Quraisy

Ruseffendi, E.T. (2006). Pengantar kepada Membantu Guru Mengembangkan

Kompetensinya dalam Pengajaran Matematika untuk Meningkatkan CBSA.

Bandung: Tarsito

Uyanto, S. S. (2009). Pedoman analisis data dengan SPSS. Yogyakarta: Graha Ilmu. 